\title{
La Voz Femenina Silenciada en los Textos Medievales: Una Carta de Teresa de Cartagena
}

\author{
Víctor Pascual Durán ${ }^{\star}$ and M. José Rodríguez Campillo ${ }^{\star \star}$ \\ Temple University, Philadelphia, USA \\ Universitat Rovira i Virgili, Tarragona, Spain
}

\begin{abstract}
In the context of medieval society, the situation of women and, more specifically, the situation of women who want to be a writer, presents a series of features that make their situation, social as well as emotional or intellectual, a complex network of conflicts, both internal and external, all related to the assumption of some male role: the desire for self-affirmation, for being an authorial self, for having the property of his thoughts, for example. Understanding and deepening in these aspects becomes a task, in many moments, exciting. This article reviews those aspects contained in the letter entitled Admiraçion Operum Dey, by Teresa de Cartagena, which are related to the feminine universe. That is, those elements that become essential to inquire into the work written by a nun in a medieval, patriarchal and eminently misogynist context in which her status as (1) woman, (2)
\end{abstract}

\footnotetext{
* Author's address:

Department of Spanish and Portuguese

Temple University

442 Anderson Hall, 1114 Polett Walk, Philadelphia PA 19122, USA

E-mail tuj26280@temple.edu

** Author's address:

Departament de Filologies Romàniques

Universitat Rovira i Virgili

Av. Catalunya 35, 43002 Tarragona, Spain

E-mail josefa.rodriguez@urv.cat
} 
judeoconversa and (3) deaf provide her with a triple marginalization. These three elements, above all, are those that shape the worldview of Teresa of Cartagena in which self-consolation becomes a means of survival in her first work, Arboleda de los enfermos and in a more brutal tone, she made a true allegation to favor the right of women to access to culture and, more specifically, to writing, in her second work that we analyze in this paper.

Keywords: Middle Ages, medieval female literature, Teresa of Cartagena, Admiraçion Operun Dey.

Resumen. En el marco de la sociedad medieval, la situación de la mujer y, más en concreto, la situación de la mujer que desea ser escritora, presenta una serie de rasgos que hacen de su situación, tanto social como emocional o intelectual, un complejo entramado de conflictos, interiores y exteriores, relativos todos ellos a la asunción de algún rol masculino: el deseo de autoafirmación, de ser un yo autoral, de tener la propiedad de sus pensamientos, por ejemplo. Entender y profundizar en estos aspectos deviene una tarea, en muchos momentos, apasionante. Este artículo revisa aquellos aspectos contenidos en la carta titulada Admiraçion Operum Dey, de Teresa de Cartagena, que están relacionados con el universo femenino. Esto es, los elementos que devienen esenciales para indagar en la obra escrita por una monja en un contexto medieval, patriarcal y eminentemente misógino en el que su condición de (1) mujer, (2) judeoconversa y (3) sorda, le reporta una triple marginación. Estos tres elementos, sobre todo, son los que configuran la cosmovisión de Teresa de Cartagena en la que la autoconsolación se convierte en un medio de supervivencia en su primera obra, Arboleda de los enfermos y en un tono más bronco, en un auténtico alegato en favor del derecho de la mujer al acceso a la cultura y, más en concreto, a la escritura, en esta segunda que analizamos.

Palabras clave: Edad Media, literatura femenina medieval, Teresa de Cartagena, Admiraçion Operun Dey.

\section{Introducción}

[...] la mirada masculina recorre con cuidado los rasgos femeninos. Los clasifica. Piensa en ellos con intensidad. No pregunta, sin embargo. Ella permanece en silencio, a la espera de algo.

(Ruiz Doménec, 1986: 26)

Admiraçion Operum Dey ${ }^{3}$ es un breve tratado de autodefensa enmarcado en el género epistolar que escribió Teresa de Cartagena.

\footnotetext{
${ }^{3}$ A partir de ahora Admiraçion.
} 
La autora previamente había publicado Arboleda de los enfermos ${ }^{4}$, una obra de autoconsolación para enfermos que pretendía ser una guía espiritual. En ella, la colectividad es la receptora de unos textos escritos por una mujer, sí, pero en los que Dios es el promotor de los mismos, y en los que la autora hace una muy astuta reinterpretación de la patrística, sin heterodoxia alguna.

Los detractores de las mujeres escritoras de su época, al conocer esta obra, arguyeron en su contra una acusación del todo inusual en la Edad Media: el plagio. Y, a raíz de ello, cuyo único fin era el de desautorizar y reprehender la figura de una mujer, monja y escritora, Teresa de Cartagena decidió componer su segunda obra, Admiraçion.

En ella, la autora mantiene las mismas estrategias que en la anterior, pero adquiere ya un tono más bronco, en tanto en cuanto se convierte, creemos, en un auténtico alegato en favor del derecho de la mujer al acceso a la cultura y, más en concreto, a la escritura.

Nos hallamos ante una carta dirigida a una "virtuosa" mujer: "Acuérdome, virtuosa señora, que me ofresci a escriuir a vuestra discreçion" (Cartagena 1967: 107). Y la mujer, en concreto, es Juana de Mendoza, dama noble y esposa del poeta Gómez Manrique.

Teresa utiliza esta táctica porque el miedo a la reacción masculina conlleva la necesidad de una audiencia femenina, de una "hermandad de precursoras y sucesoras" (Gilbert y Gubar 1984: 50) a las que dirigir sus escritos.

Ella no es la primera ni la última en hacerlo. En Teresa, como veremos, tal y como sucede con muchas otras escritoras desde la Edad Media hasta finales del siglo XIX, la autora recurre a una (¿)falsa(?) estructuración prefijada y sistémica del discurso, basada, sobre todo, en algunos fenómenos de interiorización y degradación, más que nada porque pretenden reducir, así, el impacto que pudiera tener una obra que, por el mero hecho de estar escrita por una mujer ya es, cuanto menos, en aquella época, subversiva.

De esta manera, Teresa (y otras muchas antes y después de ella) se ve en la obligación de tener que caracterizarse en términos de ausencia: ausencia de inteligencia, ausencia de ingenio, ausencia de razón, ...; en definitiva, debe y necesita excusarse por ser un no-hombre que se ha apropiado de una tarea que está única y exclusivamente diseñada para que la pueda desempeñar un hombre.

\footnotetext{
${ }^{4}$ A partir de ahora Arboleda.
} 
En esta carta, entre otras muchas cosas, Teresa de Cartagena promulga la igualdad intelectual entre el hombre y la mujer desde el seno de las estructuras patriarcales y patrísticas. Así, en el ejemplo de Judith, la mujer que en el Antiguo Testamento venció, con la ayuda de Dios, al poderoso Holofernes, Teresa encuentra la fuerza suficiente para continuar con su empresa. Y es ahora cuando se atreve a afirmar que "manifiesto es que más a mano viene a la henbra ser eloquente que no ser fuerte, e más onesto la es ser entendida que no osada, e más ligera cosa le será usar de la péñola que del espada" ${ }^{5}$ (Cartagena 1967: 120).

Esta afirmación resulta, a todas luces, trascendental, en tanto que supone una transgresión del quehacer femenino tal y como estaba estipulado entonces. Esto es: al hombre le corresponde el uso de la fuerza y a la mujer el uso de la inteligencia.

El hecho de elevar a la mujer al estatus de res cogitans, que no solo tiene derecho al acceso a la escritura, sino a ser perfectamente capaz de desenvolverla con éxito, supone una reivindicación subversiva, dado que la función de la mujer medieval se reducía a dos posibilidades, únicamente, y muy semejantes entre sí: ser esposa, ya fuera de un hombre o de Cristo. De este modo, una de sus principales tareas era la del desempeño de las funciones domésticas y la atención al esposo y crianza de los hijos -en el caso de las mujeres laicas- o llevar a cabo el cumplimiento de las obligaciones reglares -en el de las religiosas. Bajo ningún concepto se le atribuye la péñola a la mujer, pues la escritura y el ámbito público son exclusivos del hombre y, por tanto, el espacio interior y el silencio corresponden a la mujer.

\section{La Literatura Medieval: Su Concepto}

La literatura medieval es muy distinta a la que se crea hoy en día: entre otras muchas cosas, no hay, en ella, por ejemplo, una clara distinción entre ficción y no ficción -sobre todo en los mismos términos en que lo hacemos actualmentey, por ello, el concepto de literatura medieval se ha de repensar con unos ojos distintos.

En Edad Media, la mayoría de las veces, la persona "autora" de una obra no tenía por qué ser, necesariamente, la que se ocupaba de la acción de escribir,

${ }^{5}$ La negrita es nuestra. 
más que nada porque, la mayoría de la veces, estas obras acostumbraban a dictarse (fijémonos, por ejemplo, en Alfonso X El Sabio).

Además, la conciencia autorial tampoco va a ser la que hoy en día conocemos. Y, aunque va a haber durante toda la Edad Media figuras destacadas, figuras con nombre propio (Christina de Pisan, don Juan Manuel, ...) que van a expresar claramente su conciencia de autoría, la mayoría de los escritores medievales va a estar muy lejos de admitir ese rol literario autorial que le corresponde. Más aún si la persona que adquiere el rol es una mujer y, además, monja (como es el caso que ahora nos ocupa). Ellas, la mayoría de las veces, nos recalcan hasta la saciedad, por ejemplo, que se han limitado, única y exclusivamente, a transcribir lo que les ha dictado la inspiración divina.

Quizá por ser mujeres, quizá por ser monjas o, quizá, por ambas cosas a la vez, lo cierto es que, en Edad Media, la literatura escrita por mujeres presenta una serie de inconvenientes que frenan, aún más, si cabe, su transmisión y, por tanto, su estudio.

Por ello, en la Edad Media, una "mujer literata" era algo infrecuente, impensable, y eso ya se han encargado de mostrárnoslo las distintas antologías literarias cuando, por ejemplo, la mayoría de las veces, la ignoran y resta en el anonimato.

Esta ausencia (hoy en día ya sabemos que no llegó a ser tan real como nos han dicho) de fuentes escritas femeninas deviene un grave problema ya que, por ejemplo, no nos es nada fácil poder rastrear las distintas actividades diarias que ejercían las mujeres de antaño. Pero, sobre todo, nos es difícil llegar a conocer sus posicionamientos o pensamientos, ya que lo poco que conocemos de ellas nos ha llegado a través, la mayoría de las veces, de los escritos masculinos (que no suelen ofrecer una imagen muy fiable de ellas, ya que casi siempre nos las muestran como un objeto bello y poco más), pues tradicionalmente, el mundo literario, como otros muchos mundos hasta hace bien poco, era algo que estaba adscrito única y exclusivamente a los varones. 


\section{Un Cambio en la Sociedad Medieval: Escritura Mística Femenina}

Si alguna mujer aprende tanto como para escribir sus pensamientos, que lo haga y que no desperdicie el honor sino más bien que lo exhiba, en vez de exhibir ropas finas, collares o anillos...

(Pisan 2001: 5)

Como se ha podido ver, el mundo cultural, en Edad Media, estaba adscrito al ámbito masculino y, por tanto, la escritura no era, ni mucho menos, una de las tareas asignadas a las mujeres, que debían dedicarse a desempeñar sus labores como buenas esposas y madres o dedicarse al mundo conventual. Así, quedaban subordinadas, o al marido o a Dios. Sin embargo, poco a poco, la educación va a empezar a ser un campo en el que la mujer va a tener cierto espacio, pues a lo largo de toda la Edad Media se va a gestar un profundo cambio en la sociedad que, lentamente, va a hacer emerger, por ejemplo, nuevas formas de lenguaje y representación, nuevas interpretaciones de los ideales espirituales que, ahora, buscan, por ejemplo, imitar a los apóstoles y a Cristo.

Entre estos cambios, nos vamos a encontrar con el progreso de la sociedad feudal a partir de los siglos XI y XII, con movimientos que van a llevar a una reforma de la Iglesia, por ejemplo, con el hecho de que los laicos, esencialmente las mujeres, quieran participar del fenómeno religioso de una forma nueva (beguinas).

Esta nueva modalidad de participación va a llevarlas a querer descubrir "al hombre interior", y va a traer nuevas formas de devoción y nuevas prácticas de las mismas, donde las mujeres van a tener un papel bastante destacado, pues van a poder optar a una nueva vida religiosa, una nueva vida en la que van a poder ser, por ejemplo, maestras y profetas.

Partiendo de que la mayoría de la población era analfabeta y de que, por tanto, la escritura era privilegio solo de unos pocos, se le va a empezar a encargar a la mujer la transmisión de la cultura y de los conocimientos que esta pudiera poseer a sus hijos e hijas. Por ello, la mujer medieval empieza a tener un pequeño papel a la hora de transmitir la cultura escrita del momento. Pero, ¿dónde y desde cuándo ha accedido ella a la cultura?

Sabemos muy bien que: 
- En los sectores sociales bajos existía cierta igualdad entre hombres y mujeres en lo que al acceso a las letras se refería, pues la ausencia de instrucción en ambos era lo más generalizado.

- Si nos referimos a los nobles, tenemos constancia de que la mayoría de ellos sí que eran cultivados: llegaban a dominar la escritura, lectura, otras lenguas, estaban instruidos en ciencias y músicas, ... Y aquí es donde podremos encontrar a algunas mujeres dedicadas al estudio y manejo de las letras.

- Pero donde realmente estuvo el ámbito letrado durante mucho tiempo, y en esta época en concreto, fue en la Iglesia. Allí, los clérigos tenían el patrimonio casi exclusivo de las letras. Patrimonio que, poco a poco, y con el paso del tiempo, se fue secularizando.

Dentro de este ámbito religioso, las monjas eran las más afortunadas de entre todas las mujeres de la época -si nos referimos al término cultura-, ya que podían llegar a conocer latín, griego, saber leer, escribir, ... Y aunque no fuera muy común, tenemos noticias de mujeres medievales que escribieron desde sus conventos, aunque la mayoría de ellas tuviera que enfrentarse a un cuestionamiento importante, ya que sus obras llegaban a considerarse sin rigor alguno por el mero hecho de que las hubiera escrito una mujer; asimismo, también se las consideraba menos inteligentes, con menos capacidades (como es el caso de la escritora objeto de este estudio).

Hemos podido constatar que, desde más o menos el siglo VI, las mujeres que ingresaban en un convento para hacerse monjas tenían que saber leer y escribir, más que nada porque estos conventos, precisamente, y en aquella época, devinieron importantes centros de sabiduría, incluso para las mujeres nobles que a ellos se acercaban, así como "espacios de libertad" (Segura 2012: $1-2)$.

Los monasterios femeninos medievales no solo fueron, entonces, lugares a los que acudían las mujeres de la época por vocación religiosa sino, muchas veces, centros a los que ellas iban para no tener que estar sometidas a la sociedad patriarcal imperante en el momento, y donde podían dedicarse, sin temor a nada ni a nadie, a lo que ellas mismas considerasen oportuno, ya fuera a la oración, ya a la lectura o escritura.

Por ello, es en esta época cuando van a aflorar más monasterios femeninos, y prueba de esa implantación masiva es que el $99 \%$ de las escritoras medievales conocidas son religiosas. 
Así, desde el siglo XII al XV, la escritura mística femenina se va a constituir en un hecho uniforme y diverso al mismo tiempo, ya que estas mujeres escriben en distintas lenguas y distintos lugares (aunque esencialmente en el mundo anglosajón).

En el siglo XII, Hildegarda de Bingen es la iniciadora, y ya en los siglos XIII-XIV es donde más escritoras místicas vamos a encontrar (época de Teresa de Cartagena). Incluso en el siglo XIV encontramos a la primera mujer que podríamos denominar "escritora profesional laica", Christina de Pisan, autora formada fuera de los conventos, en las cortes parisinas y gracias a su padre (astrólogo y médico), que fue el que le permitió el acceso a bibliotecas y la adquisición de amplios conocimientos gramaticales o filosóficos, por ejemplo.

Así pues, durante el final de la Edad Media tenemos una unión explosiva e insólita hasta el momento: mujeres que acceden a la escritura para explicarnos su experiencia interior, sus deseos, ... Se trata, en la mayoría de los casos, de mujeres que se apropian de los instrumentos que les ofrece la escritura para hablar de sí mismas y de Dios, pues, según ellas, es Dios el que las ha llamado para ello.

Estas mujeres rompen las barreras del mundo en la Edad Media, un mundo que las había condenado al silencio, y alzan sus voces. Sin embargo, para comprenderlas, tenemos que comprender su mundo primero, tenemos que contextualizarlas: esa va a ser la intención del siguiente capítulo, un trabajo previo y necesario para recuperar y entender el significado de sus textos.

\section{La "Querella de las Mujeres"}

Callad, hombres, y no digáis que la Naturaleza solo en hacer hombres se entretenga y para formar a las mujeres no tome si no con desgana algún cuidado.

(Leonora Della Genga 1360)

Durante parte de la Edad Media y la Edad Moderna, se produjo un extenso debate en toda Europa sobre la diferencia o no entre hombres y mujeres. Así, los hombres estaban constantemente tratando de demostrar la inferioridad natural de las mujeres con respecto a ellos.

Ante esto, una serie de mujeres escritoras reaccionaron y también llegaron a cuestionarse (sobre todo a través de la literatura) el predominio del hombre 
sobre la mujer. Estas autoras intentaron ejemplificar cómo la mujer tenía las mismas capacidades que el hombre $\mathrm{y}$, muchas veces, incluso llegaron a desafiarlo.

Estas autoras, sobre todo desde los siglos XIII y XIV, van a estar reivindicando una situación más equitativa, más igualitaria y, para ellas, la literatura será un arma a utilizar a la hora de intentar lograr su objetivo.

A este "movimiento" de mujeres que pretendían establecer definitivamente la igualdad entre hombres y mujeres se le denominó la "Querella de las Mujeres", un movimiento europeo que mantuvo un encendido debate desde la baja Edad Media hasta la Revolución Francesa.

En líneas generales, se trataba de una discusión cuyos orígenes se remontaban, como ya hemos mencionado, al siglo XIII, momento en el que en las universidades se preconizó la recuperación del derecho romano y comenzaron a divulgarse distintas teorías, como la de la polaridad de los sexos, de Aristóteles, que entraba en contraposición con posturas defendidas, por ejemplo, por Hildegarda de Bingen en la centuria anterior, que defendía la complementariedad de los sexos (Rivera Garretas 1996).

Así pues, la irrupción del pensamiento aristotélico supuso un retroceso considerable en tanto y en cuanto se rechazó la idea de que hombres y mujeres tenían el mismo valor, en favor de la superioridad masculina. En los textos de la patrística pueden hallarse elementos idiosincráticos situados al mismo nivel ya que, en ellos, se insiste en los contenidos del Pentateuco y, más concretamente, en los que atañen al Génesis; esto es, la creación del mundo ${ }^{6}$ y el relato del Edén. En este último, por ejemplo, se explica que el hombre nace del barro y que la mujer nace de su costilla. Así pues, la subyugación de la mujer al hombre pertenecería al orden natural de las cosas, sería voluntad divina y, por tanto, esta visión estaría completamente justificada.

Teniendo en cuenta estos aspectos, en el seno de las universidades y de las distintas cortes europeas, se producirá entonces un agitado debate, en el que se erigirán numerosas voces misóginas y que, muy pronto, trascenderán al ámbito literario.

Una de las obras que más repercusión tuvo en aquella época fue el Roman de la Rose, compuesto por Guillaume de Lorris y Jean de Meung. La primera parte de la obra se compuso entre 1225 y 1240 y, la segunda, entre 1275 y

\footnotetext{
${ }^{6}$ Génesis $(1,26-27)$.
} 
1280. En este poema, de 21.780 versos octosílabos, y de profundo contenido misógino, la mujer es considerada como enemiga natural del hombre, y debe ser tratada como el ser irracional que es; es decir, como una bestia.

Este tipo de obras ayudaban, en gran medida, a extender el sentimiento patriarcal en detrimento de los derechos de las mujeres. Tanto es así que algunas mujeres empezaron a tener completamente vedado cualquier tipo de instrucción que no estuviera estrictamente relacionada con las labores del hogar.

Pero no todo fue negativo, pues algunas damas nobles, si su progenitor accedía, podían llegar a ser instruidas por una mujer anciana de la familia, docta en letras y de costumbres intachables, pero poco más. Por ejemplo, de Carlomagno se dice que procuró el acceso a la cultura, no solo de sus hijos, sino también de sus hijas. El Emperador estaba de acuerdo en que estas conociesen el uso de la aguja y el manejo de la rueca, tareas reservadas a las mujeres, pero pensaba que también debían conocer las letras, la aritmética, la gramática, etc.; las artes liberales, en definitiva. Y, para ello, mandó traer a palacio un preceptor que, curiosamente, no solo aleccionó a sus hijas, sino también a una de sus mujeres y a su propia hermana.

Una de las primeras voces femeninas que se erigió contra este discurso misógino fue la de la francesa Christina de Pizan, hija de una familia acomodada de Venecia que, hacia 1405, compuso La Ciudad de las Damas, obra que surge como contestación al Román de la Rosa de Lorris y Meung. En ella, la autora conversa con tres damas (Razón, Derechura y Justicia) y todas fabulan sobre la creación de una ciudad únicamente habitada por mujeres:

Debes saber que existe además una razón muy especial, más importante aún, por la cual hemos venido, y que vamos a desvelarte: se trata de expulsar del mundo el error en el que habías caído, para que las damas y todas las mujeres de mérito puedan de ahora en adelante tener una ciudadela donde defenderse contra tantos agresores. Durante mucho tiempo las mujeres han quedado indefensas, abandonadas como un campo sin cerca, sin que ningún campeón luche en su ayuda. Cuando todo hombre de bien tendría que asumir su defensa, se ha dejado, sin embargo, por negligencia o indiferencia que las mujeres sean arrastradas por el barro. (Pizan 2001: 69).

Se trata de una auténtica reivindicación feminista cuyo propósito principal es el de resarcir a la mujer de tantos y tantos siglos de violencia. En esta 
obra, la autora trata temas relacionados con la educación de las mujeres, la violación, el yo femenino autoral, la fe cristiana, etc., y, al igual que Teresa de Cartagena, "Pizan atribuyó al derecho de las mujeres a la palabra un origen divino. Y buscó y halló en el interior de su cuerpo de mujer la fuente de seguridad en su saber que le negaba el voluminoso "corpus" de literatura misógina acumulado siglo tras siglo en su entorno cultural" (VV.AA. 1998: 282).

A pesar de que, actualmente, no se dispone de datos concretos sobre la difusión de La Ciudad de las Damas en Castilla a lo largo del siglo XV, y que parece ser que Teresa de Cartagena no leyó ni supo acerca de la obra de Christina de Pizan, en el contexto castellano, el debate en torno a la posición de la mujer en la sociedad o la familia, por ejemplo, tuvo, al igual que en el resto de Europa, una gran intensidad y disparidad de opiniones entre misóginos y pro-feministas. Así pues, Seidenspinner-Núñez (1998: 2) ofrece una nómina de autores (clérigos, poetas, moralistas y escritores de prosa de ficción) que, a lo largo del siglo XV, participaron en la Querella: El Corbacho, de Alfonso Martínez de Toledo; Repetiçión de amores, de Luis de Lucena; Jardín de nobles doncellas, de fray Martín de Córdoba; Tratado en defensa de las mujeres, de Mosén Diego de Valera; Cárcel de amor, de Diego de San Pedro; Grisel y Mirabella, de Juan de Flores; Coplas en vituperio de las malas hembras y en loor de las buenas mujeres, de fray Yñigo de Mendoza y Coplas de las calidades de las donas, de Pero Torrellas.

Sin embargo, cabe destacar que las obras y autores considerados profeministas lo son, única y exclusivamente, por el hecho de intentar suavizar las posturas misóginas, realzando la belleza y la bondad de las damas. En ningún caso se procede, en ellas, a una defensa real de la mujer. El ámbito público, el estudio y la voz propia siguen siendo un territorio vedado a ellas.

Teresa de Cartagena entra de lleno en esa Querella con Admiración, obra en la que arremete en contra de los prudentes varones que se han sorprendido por el hecho de que una mujer haya publicado una obra.

No se ha hallado ningún documento que atestigüe alguna de estas críticas, únicamente las que la propia Teresa refiere en su obra. En ella, tal y como se expone en las siguientes páginas, realiza una ferviente defensa de su derecho a escribir, principalmente fundamentado por la voluntad divina: es Dios quien promueve y hace posible la empresa de la escritura femenina, así como Dios hizo posible la victoria de Judith sobre Holofernes. 
De esta manera, sus detractores no pueden poner en duda su palabra; esto es, la palabra de Dios, por lo que le lanzan una acusación de plagio, a todas luces inusual en el contexto medieval, en un momento en el que la conciencia de autoría está solamente empezando a recalar entre algunos escritores -a partir, fundamentalmente, de don Juan Manuel.

\section{Teresa de Cartagena}

Lo poco que sabemos de Teresa de Cartagena es gracias a los indicios autobiográficos encontrados en sus dos únicas obras conservadas (Cantera Burgos 1952).

Por ellos, sabemos, por ejemplo, que perteneció a la familia CartagenaSanta María. También resulta evidente que Teresa de Cartagena recibió una esmerada educación, e incluso instrucción en letras latinas, por el conocimiento de autores clásicos que rastreamos en su obra.

Su abuelo fue rabino mayor de Burgos, y se convirtió al cristianismo en 1390/91, se hizo sacerdote (tomó el nombre de Pablo de Santa María) y llegó a ser obispo de Cartagena y, más tarde, de Burgos: Francisco Cantera Burgos (1952) es quien relaciona a la escritora con la familia del influyente rabino Salomó Ha-Levi, abuelo paterno de Teresa.

Su tío, Alfonso de Cartagena, sucedió al abuelo en el obispado de Burgos, fue embajador por Castilla en un Concilio Eclesiástico y un importante escritor: los Cartagena participaron activamente en la vida eclesiástica y literaria de la época, destacando, incluso, por la calidad de sus bibliotecas.

Precisamente el testamento de este tío es uno de los documentos que probaría la filiación de Teresa de Cartagena a los Santa María pues en una de las clausulas reza lo siguiente: "A Terese moniali centum florines ad aliquod sub sidium sustentationes" (Cantera 1952: 537).

$\mathrm{Su}$ familia mantuvo un estrecho vínculo con la vida social, eclesiástica y política de la Castilla de los siglos XIV y XV. Eran una familia muy prominente a la que no afectaron para nada los estatutos anti-conversos (1449) que obligaron a muchos conversos a abandonar los puestos públicos que ocupaban.

Se llegaron a vincular a familias muy importantes de la época. Por ejemplo, con la de Gómez Manrique, a cuya esposa dedica Teresa de Cartagena su Admiraçion y, tal vez, Arboleda, la primera. 
Los padres de Teresa fueron Pedro de Cartagena (fundador del mayorazgo de los Cartagena) y María de Saravia.

Ella, Teresa, nació entre 1415 y 1420, quedándose huérfana a los 15 años.

Sabemos que estudió en Salamanca (la propia Teresa nos lo menciona), pero con tutores de la Universidad, pues no hay indicio alguno de que asistiera a sus aulas, ya que no consta su nombre en ningún registro de la misma.

Desde bien joven, se fue quedando progresivamente sorda.

En 1453 la encontramos en un convento, parece ser que franciscano, aunque no se sabe con certeza, pues en las dos obras de Teresa se omite a qué orden pertenecía la escritora, aunque a este respecto, en la actualidad, Isaac Rilova (2009) parece desentrañar el asunto: Teresa de Cartagena, hacia 1445 ingresó en el convento franciscano de Santa Clara de Burgos y en 1449 se cambió al de Santa María la Real de la Huelgas, de la misma ciudad. Este hecho estaría probado por dos escritos de su tío, Alonso de Cartagena, recogidos en el Bulario de la Universidad de Salamanca y fechados el 3 de Abril y el 2 de Mayo de 1449, respectivamente, donde se solicita la dispensa papal para que Teresa pueda pasar de la orden franciscana a la cisterciense. La motivación de dicho cambio: la poca tolerancia de las clarisas hacia las monjas de ascendencia judía y la preferencia de los conversos y de la alta nobleza castellana por la orden cisterciense.

$\mathrm{Su}$ vida, a partir de ahora, se va a caracterizar por una triple marginalidad: proveniente de una familia de conversos, sorda y mujer. Y esta triple marginalidad va a marcar su obra.

El aislamiento del mundo (por su sordera, sobre todo, pero también por su condición religiosa), la lleva a producir su primer tratado, Arboleda, con la intención de consolar a las personas enfermas, como ella misma.

La obra fue leída dentro y fuera del convento donde ella profesaba y, a causa de ello, surgieron los primeros detractores, que criticaron su afición a escribir y rechazaron directamente la posibilidad de que esa obra estuviera escrita por una mujer.

Como respuesta a todas las críticas que suscitó esta obra, Teresa de Cartagena volvió a escribir: esta vez Admiraçion, una carta en defensa, sobre todo, de su condición de mujer y escritora. 
Arboleda define el valor espiritual del sufrimiento físico, desarrolla el camino de superación a través del sufrimiento e inserta elementos autobiográficos que la acercan más al público, pues nos ofrece su vida a modo de exemplum. Teresa, que ha sufrido en sus propias carnes el dolor, predica paciencia y resignación, e inicia un camino de rectitud y alabanza que, si lo seguimos, nos llevará a la perfección.

El tratado Arboleda tiene una disposición lógica: se estructura en torno a imágenes en las que se combina la vida conventual con el propio padecimiento, apoyándose, con mucha frecuencia, en citas bíblicas y entretejiendo imágenes que se refuerzan y enriquecen entre sí.

La otra obra -objeto de estudio en este artículo-, Admiraçion, fue escrita, según cuenta la propia autora, a petición de doña Juana de Mendoza, posee una intención didáctica y se dirige a los enfermos del alma (la anterior obra la había dirigido a los enfermos del cuerpo). En ella, emplea distintos recursos para defender el derecho (y, por amplitud, el derecho de todas las mujeres) a la escritura.

Así, la alusión bíblica a la historia de Judith y Holofernes ayuda a Teresa a demostrar que, para una mujer, es más fácil la actividad intelectual que la física. Además, menciona que Dios y su poder son los que la han inspirado en su escritura y, por ello, no hay nada "reprochable" en la misma.

Teresa de Cartagena tenía la cultura y preparación necesarias para dedicarse a las letras y su "apología" no puede ni debe considerarse una reivindicación feminista: ella misma se encarga de explicitar cuál es el lugar que le corresponde a la mujer y qué tareas son apropiadas para su sexo: casarse y atender a su hogar o a Dios, como ella misma hacía.

Su defensa va por otro camino: el hecho de que los hombres monopolicen la actividad literaria no debe ser considerado como algo irrefutable, pues tanto hombres como mujeres son iguales en espíritu y, por ello, ambos pueden ser imbuidos de la gracia de Dios para escribir. Así, la conclusión que extraemos al leer Admiraçion es que los hombres y las mujeres son iguales ante Dios y su gracia debe estar repartida entre ambos. 


\section{La Carta de Teresa de Cartagena: "Admiraçion operum Dey"}

Admiraçion es un breve tratado de autodefensa enmarcado en el género epistolar. Teresa de Cartagena, previamente, publicó Arboled $a^{7}$, una obra de autoconsolación para enfermos que pretende ser una guía espiritual para rentabilizar la dolencia física en favor de la perfección moral y el consiguiente acercamiento a Dios.

En esta obra segunda, Teresa se dirige a los enfermos del alma, que se niegan a ver que la potencia de Dios actúa a través de una delicada y débil mujer.

La defensa de su situación como autora original se basa en su condición de "voz" proveniente de la "Máxima Autoridad": el Señor le concede su Gracia para hacer un tratado tanto a hombres como a mujeres.

El papel que ejerce como autora y su presencia en el texto están perfectamente calibrados en toda una serie de fenómenos de autodegradación en el ámbito personal (como mujer, monja y sorda), en el ámbito espiritual, así como el de su propia producción literaria. Ella solo hace lo que está al alcance de su "entendimiento flaco y mugeril" (Cartagena 1967: 112), y lo hace, por supuesto, con la ayuda de Dios: él le otorga el don de la Gracia para poder expresarse.

El contexto de esta misma también se enmarca, de manera intencionada y muy lograda, en lo que en siglo XV podría considerarse medianamente aceptable para una mujer: el género epistolar y, por lo tanto, el ámbito más o menos privado.

A pesar de lo anterior, el elemento que dota de una base sólida e irrefutable su autoridad autoral es la apropiación -a ojos de sus detractores-, indebida, del discurso patriarcal presente, tanto en las Sagradas Escrituras como en la sociedad bajomedieval.

Teresa de Cartagena, gran conocedora de la Biblia, cita en numerosas ocasiones fragmentos de los Padres de la Iglesia para, a través de su interpretación, dotarse a sí misma de autoridad, siempre bajo el mismo precepto: la voluntad divina.

\footnotetext{
${ }^{7}$ Ambos documentos ocupan sesenta y seis folios del ms. h-III-24 de la Real Biblioteca del Escorial, publicados por Lewis J. Hutton en 1967 en una cuidada edición paleográfica.
} 
Así, sus detractores ${ }^{8}$ se ven incapacitados e inhabilitados para refutar el contenido de Arboleda, ya que hacerlo supondría estar bajo sospecha de heterodoxia. Por tanto, optan por poner en duda la valía de Teresa, acusándola de plagio.

Nuestra autora, ante tal situación, decide tomar cartas en el asunto y aborda la empresa de su propia defensa bajo el formato de una carta dirigida a Doña Juana de Mendoza:

Aquí comiença vn breue tratado el qual co[n]uinientemente se puede llamar Admiraçión operum Dey. Conpúsole Teresa de Cartajena, religiosa de la horden de [...] a petiçión y ruego de la Señora Doña Juana de Mendoça, mujer del Señor Gomes Manrique.

Acuérdome, virtuosa señora, que me ofresçí a escreuir a vuestra discreçión [...] (Cartagena 1967: 107).

Tal y como hemos mencionado anteriormente, Teresa, desde un punto de vista estratégico, enmarca su producción en el género que le es permitido, y en las condiciones adecuadas: una mujer instruida de familia influyente que escribe a petición de una dama noble.

La religiosa comienza la carta disculpándose por el retraso, aduciendo problemas de salud. Y a pesar de la importancia del componente de la enfermedad en la cosmovisión teresiana, en esta ocasión hace referencia única y exclusivamente a las críticas recibidas por la publicación de Arboleda:

Sy consyderardes, virtuosa señora, las enfermedades e corporales pasyones que de continuo he por familiares, bien conosçerá vuestra discreçión que mucho son [...] turbadoras del entendimiento. [...] E avn con todo esto ya sería pagada este debda que por mi palabra soy debdoras y la soledad mí[a] se contentase con solos mis corporales afanes y no me causase conpañía secreta e dañosa llena de ynteriores conbates y espirituales peligros con muchedunbre de vanos e variables pensamientos, los quales asý como una gueste de gente armada çercan de cada parte la angustia[da] ánima mía. Pues, ¿qué hará el entendimiento flaco e mujeril desque se vehe puesto entre tantos e tan peligrosos lazos? Ca en defenderse de aquello que so color de bueno el

\footnotetext{
${ }^{8}$ No tenemos noticia de quiénes fueron, únicamente conocemos las referencias que
} hace al respecto la propia Teresa en Admiraçion. 
nuestro adversario le ofreçe son tanto enflaquecidas sus fuerças que sy la Virtud soberana no le esfuerça e alunbra, no es en él virtud ni santidad alguna. Asý que, muy discreta señora, syenta vuestro discreto sentido la diversydade calidad destos espirituales e ocultos escándalos con otros de no menor calidad e cantidad que vuestra prudençia puede bien entender... (Cartagena 1967: 111-112).

Después de poner en situación a su interlocutora, Teresa comienza con la relación de agravios que se han ido vertiendo en su contra, siendo el eje central de la crítica la misoginia:

Ca manifiesto no se faze esta admiraçión por meritoria de la escritura, mas por defecto de la abtora o conponedora della. (Cartagena 1967: 113).

Así como el plagio:

Pero ay otra cosa que [no] devo consyntir, pues la verdad non la sonsyente [...] porque me dizen, virtuosa señora, que el ya dicho bolumen de papeles bor[r]ados aya venido a la notiçia del señor Gómez Manrique e vuestra, no sé sy la dubda, a bueltas del tractado se presentó a vuestra dicreçión. E como quier que la buena obra que antel subjeto de la soberana Verdad es verdadera e çierta, non enpeçé mucho si nel acatamiento e juizio de los nombres $\mathrm{v}$ manos es avida por dubdosa. (Cartagena 1967: 114).

Aunque en ambos tratados son constantes los fenómenos de degradación para captar la benevolencia del lector y, consecuentemente, minimizar los efectos directos y colaterales de su osadía, en Admiraçion notamos un cambio sustancial en cuanto a su posición respecto a sí misma y a su obra, por lo que podemos vislumbrar la no asunción de dichos fenómenos, en lo que correspondería a otra estrategia estructural de su empresa.

Teresa realiza un análisis lúcido, aunque en clave irónica, sobre la naturaleza de las críticas y, con la mayor ortodoxia, realiza una auténtica defensa de su derecho como mujer a la escritura.

Si bien en un principio el motivo de su sordera es empleado como un elemento degradante, puesto que las enfermedades en la Edad Media eran tenidas 
como un castigo divino por comportamientos pecaminosos, en el avance de su discurso, a través de la reinterpretación de la patrística anteriormente mencionada, se convierte en el elemento que ordena su cosmovisión, la aleja del pecado y, a través del sufrimiento que le produce, la acerca a Dios.

Este hecho es significativo en tanto en cuanto es Dios quien considera a Teresa como un sujeto digno de redención, de acceder al conocimiento y, por consiguiente, a la voz.

Así, Teresa de Cartagena se considera legitimada para el ejercicio intelectual:

Asý que, tornando al propósyto, creo yo, muy virtuosa señora, que la causa porque los varones se maravillan que mujer aya hecho tractado es por no ser acostumbrado en el estado fimíneo, mas solamente en el varonil [...] Ca esta ynperfiçión e pequeña $<\mathrm{e}>$ sufiçiençia pu[é]dela muy [bien] reparar la grand[eza] divina e avn quitarla del todo e dar pe[rf]içión e abilidad en el entendimiento fimíni o asý como en el varonil, ca la sufiçiençia que han los varones no la an de suy[o], que Dios geladió e da. Onde el Apóstol dize ${ }^{9}$ : "No somos y dionios o suficientes de cogitar alguna cosa de nosotros asý como de nosotros mesmos; ma[s] la nuestra sufiçiençia, de Dios es." (Cartagena 1967: 115-116).

De esta manera, deja atrás ciertos postulados aristotélicos, tan arraigados en la sociedad medieval, especialmente desde el siglo XIII.

Sin embargo, en la negociación que lleva a cabo entre su propio discurso y el patriarcal, nuestra autora acepta ciertas cuestiones relativas a la tradición bíblica, como la sumisión de la mujer al hombre y, por supuesto, a Dios. En este sentido, apoya, también, su permanencia en el hogar, al cuidado de los hijos y de las labores domésticas, constituyendo la única alternativa la vida monacal. Aunque, tal y como hemos apuntado anteriormente, Teresa no renuncia, en ningún caso, al acceso de la mujer a la escritura y a la cultura. Así, expone el proceso mediante el cual Dios, en su infinita misericordia, le ha infundido el conocimiento.

El Señor, explica, a través de la sordera la aísla del mundo y, sobre todo, de actitudes pecaminosas. En un acto de resignación, renuncia al deseo de recuperar el oído, pidiendo la salvación de su alma. El férreo compromiso de

${ }^{9}$ II Ad Corintios 3: 5 
no volver a alejarse del camino de la perfección espiritual reporta a Teresa la administración divina de la capacidad intelectual:

Ca estas otras naturales çiençias buenas son, pues Dios las cría e las inxirió en el entendimiento de los onbres. Pero sabemos que muchos de los que aquestas çiençias supieron se perdieron e otros muchos que no las sabían se saluaron. Pues solamente aquélla es verdadera çiençia que nos enseña e endereça e atrae a conosçer e amar e desear el verdadero Bien, e aquesta sabiduría no 1[a] niega Dios a quien la desea e busca con entrañable cuidado. (Cartagena 1967: 128).

Con la excusa de la loanza a Dios, expone toda una serie de elementos relativos a la creación, a la naturaleza del hombre y de la mujer y las relaciones entre ambos, apoyándose siempre en los textos patrísticos, con un fin muy concreto: el resarcimiento de su yo autoral.

Con el ejemplo de Judith, Teresa encuentra en el Antiguo Testamento a una aliada inestimable. Por una parte, constata que, mediante la intervención divina, una mujer es capaz de realizar cualquier tipo de actividad, incluso vencer a un temido general -como es el caso- y, por otra, ensombrece su osadía:

Bien paresçe que la industria e graçia soberana exçeden a las fuerças naturales e varoniles, pues aquello que grant exérçito de onbres armados no pudieron fazer, e fízolo la yndustria e graçia de vna sola muger. E la yndustria e graçia, ¿quién las ha por pequeñas preminençias syno quien no sabe qué cosas son? Çiertamente son dos cosas asý syngulares que a quien Dios darlas quiere, agora sea varón o sea henbra, marauillosas cosas entenderá e obrará con ellas sy quisiere exerçitarse e no 1[a]s encomendar a oçiosidad y nigligençia. Pues sy Dios negó al estado fimineo graçia [e] yndustria para hazer cosas dificultosas que sobran a la fuerça de su natural condición, ¿cómo los negará la graçia suya para [que] con ella e mediante ella sepan e puedan fazer alguna otra cosa que sea más fáçile o ligera de fazer al sexu fimineo? Que manifiesto es que más a mano viene a la henbra ser eloquente que no ser fuerte, e más onesto la es ser entendida que no osada, e más ligera cosa le será vsar la péñola de que del espada. Asý que deven notar los prudentes varones que Aquél que dio yndustria e graçia a 
Iudit para fazer vn tan marauilloso e famoso acto, bien puede dar yndustria o entendimiento e graçia a otra qualquier henbra para fazer lo que a otras mujeres, o por ventura algunos del estado varonil no s[ab]rían. (Cartagena 1967: 119-120).

Se trata, así pues, de toda una declaración de intenciones. Después de poner de relieve las hazañas que una mujer puede llegar a realizar -aunque siempre bajo el amparo de Dios- realiza una afirmación inusitada en el contexto castellano: eleva a la mujer a la categoría de res cogitans. En este momento, Teresa dinamita toda una serie de concepciones misóginas relativas al pensamiento medieval.

El hecho de afirmar que a una mujer le es más honesto ser entendida que no osada es, en el atardecer de la Edad Media, toda una osadía, pues a una mujer se le imponía el silencio, el ámbito doméstico o conventual, la ausencia de pensamiento, de dignidad; en definitiva, la falta de identidad.

El tránsito hacia la esfera pública, la dotación de pensamiento y voz propios, la construcción de la identidad femenina y, en última instancia, la creación de un yo autoral, son elementos rutilantes que dotan al texto de una singularidad excepcional en la Castilla bajomedieval.

Sin embargo, tanto la figura de Teresa de Cartagena como sus escritos han pasado completamente inadvertidos -tal y como apunta Deyermond- hasta la publicación de una breve reseña de Amador Giner de los Ríos en Historia crítica de la literatura española (1865) y, posteriormente, la publicación en Apuntes para una biblioteca de escritoras españolas (1905) de Manuel Serrano y Sanz.

No será hasta la llegada de la segunda mitad del siglo XX, con el auge de la crítica feminista, cuando se preste atención a la obra de nuestra escritora, tanto por la singularidad de la misma como por la elocuencia y energía de su protesta.

\section{Conclusiones}

A lo largo de este artículo hemos visto cómo, durante generaciones y generaciones, las mujeres han vivido confinadas en el silencio y la sumisión al poder masculino. La mayoría de ellas lo ha respetado, ha interiorizado, más o menos, durante siglos, ese limitado marco vital, ese rol. Sin embargo, algunas 
han escapado a esas normas y han tratado de desarrollar su inteligencia y su talento, logrando comunicarse a través de sus propias palabras, algunas de ellas no se han resignado a su suerte $y$, aunque no pudieron cambiar la sociedad en que vivían, al menos, se quejaron de ella, como fue el caso de Teresa de Cartagena.

Como hemos estado viendo, la situación de la mujer que quería coger la pluma en la Edad Media era sumamente compleja. Ya a partir del siglo XIII se empezó a desarrollar una corriente de mujeres escritoras que, en la medida de lo posible, intentó revolucionar el panorama literario y social, puesto que empezaron a incursionarse en un terreno que, hasta el momento, era masculino.

Casi todas ellas encontraron la fuerza necesaria para acometer la escritura en Dios, al igual que Teresa de Cartagena y, por ello, todas escribieron para dejar constancia de su experiencia con el Señor, a petición suya.

Teresa de Cartagena vive en un momento en el que la "Querella de las Mujeres" está en pleno vigor y, por lo tanto, ella sufre en sus propias obras los efectos colaterales de la misma, sobre todo al publicar su primera obra, Arboleda. Por ello, se la acusa de plagio y, ante tal situación, Teresa decide escribir la segunda, Admiraçion.

En este último trabajo, en forma de carta, la autora ya sí construye una auténtica protesta y un alegato en favor del derecho de la mujer al acceso a la cultura y, más en concreto, a la escritura y, con los elementos de que dispone, Teresa de Cartagena realiza una enérgica empresa, marca un hito en las letras hispanas al erigirse como la primera voz combativa contra el sistema patriarcal. Sin embargo, no debemos pensar que, en un contexto pre-humanista, esa defensa de la mujer alcance, satisfactoriamente, ni mucho menos, las pretensiones del pensamiento feminista contemporáneo, aunque en algo debió ayudar al mismo.

Teresa de Cartagena es una figura que pasa desapercibida hasta prácticamente la segunda mitad del siglo XX. Probablemente, el hecho de ser mujer y la brevedad de su obra hayan contribuido a esa anonimia pero, sin duda alguna, sus textos tienen una importancia capital para el estudio de la baja Edad Media. Su obra constituye un punto de inflexión en las letras hispánicas en el contexto de la "Querella", dadas las circunstancias de su producción y, fundamentalmente, por estar escritas por una mujer medieval. 
La astucia en la composición y el buen manejo de la retórica hace de su obra un elemento imprescindible para el estudio de la época, de la literatura, y de las características propias del ambiente pre-humanista de la Castilla de la segunda mitad del siglo XV.

\section{Bibliografía}

1. Ariès, Ph. \& Dubi, G. (dir.) (1989). Historia de la vida privada. Madrid: Taurus.

2. Arriaga, M., Cerrato, D. \& Nadales, M.R. (2012). Poetas italianas de los siglos XIII y XIV en la Querella de las mujeres. Sevilla: ArCiBel.

3. Cabanes Jiménez, P. (2016). Escritoras en la Edad Media. Espéculo, 33.

4. Cantera Burgos, F. (1952). Alvar García de Santa María y su familia de conversos: historia de la judería de Burgos y de sus conversos más egregios. Madrid: Instituto Arias Moreno.

5. Cartagena, T. de (1967). Arboleda de los enfermos y Admiraçión operum Dey. Lewis Joseph Hutton (ed.). Madrid: Anejos del Boletín de la Real Academia Española, Anejo XVI.

6. Deyermond, A. (1976). El convento de dolençias: The Works of Teresa de Cartagena. Journal of Hispanic Philology, 1:19-29.

7. Gilbert, S., Gubar, S. (1984). The Madwoman at the Attic. New Haven \& London: Yale University Press.

8. Mandingorra Llavata, M.L. (2002). La configuración de la identidad privada: diarios y libros de memorias en la baja Edad Media. In Actas del V Congreso de Historia de la Cultura Escrita. Escritura y clases populares (pp. 217-235). Alcalá de Henares: Publicaciones de la Universidad de Alcalá de Henares.

9. Navarro Bonillo, D. (2004). Del corazón a la pluma. Archivos y papeles privados femeninos en la Edad Moderna. Salamanca: Ediciones de la Universidad de Salamanca.

10. Pisan, C. (2001). La ciudad de las damas. Madrid: Ediciones Siruela (Biblioteca Medieval VII).

11. Rilova Pérez, I. (2009). Los Cartagena: una familia comprometida con la cultura y el pensamiento en Burgos del siglo XV. Estudios mirandeses: Anuario de la Fundación Cultura "Profesor Cantera Burgos", 29: 173-192.

12. Rivera Garretas, M.M. (1996). La querella de las mujeres, una interpretación desde la diferencia sexual. Política y Cultura, 6: 25-39.

13. Ruiz Doménec, J.E. (1986). La mujer que mira. Barcelona: Quaderns Crema.

14. Seidenspinner-Núñez, D. (1998). The Writings of Teresa de Cartagena. Cambridge: Boydell \& Brewer Ltd.

15. Segura, C. (2012). Los monasterios femeninos medievales fueron espacios de libertad y sabiduría. Diario Sur, Logroño, 22 de julio de 2012. 
16. Vicente García, L.M. (1989). La defensa de la mujer como intelectual en Teresa de Cartagena y Sor Juana Inés de la Cruz. Mester, 18(2): 95-103.

17. VV.AA. (1998). Biblia de Jerusalén. José Ángel Ubieta López (dir.). Bilbao: Desclée de Brouwer.

\section{Authors' Biodata}

Víctor Pascual Durán es graduado en lengua y literatura hispánicas y máster en enseñanza de español como lengua extranjera por la Universitat Rovira i Virgili. Actualmente es doctorando y graduate teaching assistant en el Department of Spanish and Portuguese del College of Liberal Arts de la Temple University en Philadelphia (USA).

M. José Rodríguez Campillo es doctora en literatura española por la Universitat Rovira i Virgili. Actualmente es investigadora SECTI en la Universitat Rovira i Virgili y, con anterioridad, profesora asociada en la misma. Es especialista en Literatura Española de los Siglos de Oro. Su tesis doctoral sobre las Implicaturas en el teatro femenino de los Siglos de Oro constituye un claro ejemplo de la investigación desarrollada por la Dra. Campillo en la que se concede una importancia fundamental a la interdisciplinariedad. La utilización de métodos lingüísticos para el análisis literario es una constante en sus artículos publicados en revistas y volúmenes monográficos. Ha participado en numerosos congresos internacionales y ha organizado reuniones científicas en las que se pretende fomentar la visibilidad de la literatura escrita por mujeres. 